\title{
The Codex's Contents: Attempt at a Codicological Approach
}

\begin{abstract}
During the preparation of the revised English version of La Syntaxe du codex, the authors highlighted the need to reconsider the current notion of 'content' from a codicological point of view, in order to complement the more traditional textual and philological perspectives. This contribution offers a first overview of an ongoing reflection on the identification and delimitation of the various types of contents that can be found in a codex including the notions of BlocConts and UniConts. The analysis of contents raises a number of (partially open) questions concerning their interaction, aimed at a better understanding of the structure of the codex, as well as of its genesis and subsequent transformations.
\end{abstract}

Several reasons led us, a few years after the Syntaxe du codex was originally published, to consider producing a revised and updated edition in English, which should soon appear with the same publisher. ${ }^{1}$ Our revision turned out to be longer and more complex than expected and the original text of the Syntaxe has undergone substantial additions and rethinking concerning several points, including the multi-faceted notion of Content. In this contribution, we summarize

1 Andrist, Canart and Maniaci 2013. We were first of all pleasantly surprised to learn that all the copies of the book had been sold just one year after its publication. Second, we received valuable and stimulating comments and suggestions from some competent readers and reviewers which helped us see that certain points of our reasoning required further clarification or improvement. Third, we realised that our French prose was not entirely clear to some nonnative speakers: not only has the language barrier in general probably slowed the diffusion of the book among scholars interested in the complexity of the medieval codex, but some of our technical statements may have been, understandably, misunderstood by some readers; the English edition therefore also aims to broaden the circle of our readers and to encourage their reactions and comments.

While preparing this second edition we felt the constant absence of the French edition's third co-author, our dear friend Paul Canart, who sadly left us in September of 2017 and would undoubtedly have efficiently contributed to and immensely enjoyed preparing this new edition with us. 
our additional reflection on this topic and share with the readers some more prospective questions beyond those touched upon in our monograph. ${ }^{2}$

\section{The basic types of content}

The term content - generally designating what can be found in a codex (texts, images, musical scores, etc.) - is currently used in different ways but is not formally defined in technical literature. It therefore seems useful to better clarify its use. ${ }^{3}$

At first approach, we understand the content of a codex as follows:

Content: 'In a codex, the whole of the finite sets of signs that convey a message'.

These 'signs' can be letters, drawings, the elements of a miniature, and so forth. As for the adjective 'finite', in the context of the codex it means that the set of signs is a complete message, more or less corresponding to the one that the person(s) in charge of its copy originally transcribed (a whole text, for example, or a subset of a text, or all of a reader's marginal notes) and that it can be independently understood as a whole, without being divided into smaller units of meaning or grouped into bigger ones. ${ }^{4}$ This definition is extended to contents whose copy was not completed and those which were mutilated as a result of a transformation of the codex.

Each of these sets of signs can be loosely called a piece of content. ${ }^{5}$

In the original Syntaxe (hereafter Syntaxe 1), content as a general notion was divided into the two categories of main contents (contenus principaux, including 'whole works or copies thereof, images, decorations, musical scores, a mixture of these previous categories, marginal notes to a text, and so forth') and

2 In recent years Michael Friedrich has followed our work very closely with his lively scientific curiosity, providing us with stimulating discussions and valuable comments for which we are deeply grateful to him.

3 On the complexity of the notion of content, see Maniaci 2004, 82-86; Andrist 2016, 18-22.

4 We understand the concept of 'finite set of signs' exclusively within the context of a specific manuscript. For example: in a codex of Homer, every book is a finite set of signs; if a user writes a comment, it is also a finite set of signs; if, in another codex, someone copies the first lines of the Iliad in an empty spot, this is also, for this codex, a finite set of signs. As explained below, the notion of 'finite message' can operate at several levels and cannot always be applied unambiguously to delimit content (see p. 376).

5 On the limits of this definition and the notion of piece of content, see below, p. 376. 
accessory contents (contenus accessoires, such as 'ownership notes, shelfmarks, scribbles, probationes calami, obituaries, succession marks' and so forth). ${ }^{6}$ Decoration of the binding was assigned to the second category as a special case, but was in fact excluded from our systematisation; we were not unaware of the unsatisfactory nature of this choice. ${ }^{7}$ In the new, English edition (Syntax 2) a deepening of our thinking has led us to better qualify the previously introduced categories and relate them to the codex's evolutionary history. We now distinguish three kinds of content within a codex:

Basic Content: 'content which is intended to be received, shared, and transmitted by the codex (such as copies of works, images, musical scores, a mixture of these, their direct paratexts, a scribe's or reader's marginal notes on a text, and so forth)'.

Functional Content: 'content which makes the reception, sharing, and transmission of the basic contents possible or easier (such as quire signatures, folio numbers, owner stamps and notes, shelfmarks, etc.)'.

Ancillary Content: 'content which is non-functional and which is not intended to be received, shared, or transmitted by the codex (such as scribbles, probationes calami and so forth)'. ${ }^{8}$ There are clearly several kinds of ancillary contents, although we leave here open the question of their exact extent (should they, for example, include 'book fillers', or are those rather a type of basic content?). A special case is represented by the palimpsests: the original contents on a codex's palimpsest leaves do not belong to the new book project and thus does not strictly belong either to the new book's production, even if they have been more or less inadvertently included into it. This original content is chronologically earlier than the new book content but totally extraneous to it, and it can therefore be considered as an ancillary content, not in itself or in the project in which it was originally copied, but from the specific perspective of the new book.

A codex's basic contents consist in a series of pieces of content, such as texts, images, musical scores, or sometimes a mix of these. ${ }^{9}$ These pieces of content (or, for the sake of simplicity, 'contents') are usually distinguished from one

6 'Nous distinguons entre les contenus principaux (œuvres ou copies d'œuvres, images, décorations, partitions musicales, un mélange de celles-ci, des notes marginales sur un texte...), et les contenus accessoires (notes de possession, cotes du manuscrit, graffiti, probationes calami, obit, marques de succession)', Syntaxe 1, 51.

7 'Un cas très particulier de contenu accessoire est constitué par la décoration de la reliure', Syntaxe 1, 51.

8 These have also been called 'side content' see Andrist 2018, 137-138, 143-146.

9 We always mean 'series' or 'set' as a collection of objects that contains at least one object. 
another by a significant material division, but the situation can be more complicated, as we will discuss it below.

Most pieces of content are made up primarily of texts, or 'words written in a significant order'. ${ }^{10}$ Among these one must distinguish between the pieces of basic content which

- $\quad$ are (supposedly) copies of pieces of basic content already existing in another manuscript (the antigraph of the piece of basic content, which is its apograph); ultimately, they usually go via a first copy ${ }^{11}$ back to a 'work', which is usually an artistic creation; and

- $\quad$ pieces of basic content created for a specific codex, such as first copies (including many book epigrams), as well as colophons or the like.

It is then possible to define:

- the work: 'a production of the human mind which can be materialised in a book', and

- the work copy (or witness): 'in a manuscript, each materialisation of a work or a given part of a work'. Work copies or witnesses are also sometimes simply called 'texts', but the high degree of polysemy of this term makes it unapropriate for such an usage. Usually, in a codex most pieces of content are first or successive copies of a work.

Up to this point we have illustrated the how our thoughts on the subject have evolved, as presented in the forthcoming Syntax 2. But the notion of content can be further considered in light of the attention recently given to the several ways that the overall content is structured in a codex, which has led to the introduction of new concepts, such as those of modular units and unbroken series. ${ }^{12}$

In the following pages we concentrate on a neglected 'building block' of a codex's content, the UniCont, which we introduced already in Syntaxe 1, but whose implications have not yet been sufficiently accounted for. We are not presenting here the end result of a definitive model: our intention is rather to share some preliminary thoughts with anyone interested in entering the discussion.

10 Syntaxe 1, 51, 'une suite de mots dans une séquence significative'.

11 Copy is understood here in broad sense: since works are intellectual creations, the first time they are materialised as such is, in this sense, already a copy, which we call first copy. Similarly, the first copy is also a witness (the best possible one!) to the work. This is not here the place to discuss text transmission phenomena.

12 Maniaci 2004, 79-81; Andrist 2020, 8-9. 
As in Syntaxe 1 and Syntax 2, we focus on books in codex form, as a distinct subset of 'objects with a content'.

\section{Delimitation of 'Content Units' and identification of witnesses}

Both versions of our monograph deal with the concept of Content Units ('UniConts') and offer clues for how to recognise their boundaries. Nevertheless, the theoretical problems behind this notion are not dealt with: for example, not discussed in the Syntax 2 are the links and differences between UniConts and the above-defined pieces of content, or how the notion of UniCont can be related to neighbouring research areas such as philology or paratext studies.

In the following pages we discuss UniConts more thoroughly, introducing further details and new questions. We refer primarily to codices as they were originally produced: the implications of possible transformations undergone by a codex for the analysis of its contents will be dealt with in a further stage of our reflection.

Our starting points are the basic ideas that:

- a codex is the result of a book project whose content is an essential part thereof; ${ }^{13}$

- usually at least one piece of basic content is a witness and

- the criteria for identifying the boundaries between a codex's pieces of content must be found primarily in the codex itself, even though external clues may also be often useful.

\subsection{Delimiting UniConts}

Let us consider first a codex whose basic content is made up of texts only. How can the sequence of words constituting a text be broken down into relevant pieces of content?

Can the physical arrangement of the content on the pages provide the answer? For example, can any visual device separating one portion of text from the other portions (such as headings, blank spaces or distinctive scripts, including majuscule initials or coloured letters) be considered a valid clue for identifying

13 As a result, our remarks exclude codex-like objects which do not bear a content. 
the boundaries between pieces of content? Because of their variety and frequency, these devices would mechanically split the text into a large number of smaller portions of text (which are called Elements of content (ElConts) in the Syntaxe 1$)^{14}$ and the resulting division would lose any operative value: even though some of these ElConts can be significant, in fact the boundaries of only a small fraction of them might chance to coincide with the boundaries between the witnesses.

As a result, we cannot escape having to take into consideration the meaning of the sequences of words. And indeed, our definition of content requires that it conveys a message.

If one is sufficiently familiar with the language, as well as with the common visual hierarchy of the separating devices in the book tradition to which the codex belongs, one should be able to group most of the ElConts that belong together and isolate the main pieces of content. For example, in the Western tradition, one quickly recognises the main visual content markers, such as decorative elements which usually correspond to major content discontinuities, or other specific layout features usually marking the beginning or end of the pieces of content, as well as the boundaries of small ElConts written in a special ink and / or script, and / or layed out differently from the rest of the text. By identifying these small ElConts as well as the beginning and the end of larger ones, one should also be able to a) recognise the presence of headings, colophons or other accompanying texts; b) group together the ElConts which are closely related through their meaning into Blocs of Content (BlocCont); c) hypothetically identify the main pieces of contents and locate their probable borders, even without being familiar with the corresponding works.

However, this approach is not always without problems.

If the analysts do not have any other information apart from what is found in the codex they are examining, it is difficult for them to evaluate what has probably been copied from the model, and what was introduced by the producers; this is particularly true about the paracontents..$^{15}$ Besides they cannot either reach any fully certain conclusion about the extent of the works it contains and

14 Syntaxe 1, 104-108: the ancient definition of ElConts also includes the rare situation where there are no visual devices between the copy of two works.

15 We understand paracontents as, in a codex, pieces of content whose presence depends on one or several other pieces of content in the same codex semantically (on this definition, see Andrist 2018). As explained below, they belong to the same content type as the piece(s) of content they depend on. On the concept of paracontent, see Ciotti et al. 2018; if the paracontent is a text, it can be called 'paratext'. 
the quality of the copy, because of possible scribal mistakes and transmission accidents.

There are in fact cases where the content division in a manuscript is aberrant, for example when a scribe unduly divides a coherent ensemble because of a distraction or a misinterpretation of the antigraph, or inversely joins together two texts which do not make sense together because the transition between them has been overlooked (or had been already overlooked earlier in the tradition). Such situations occur very frequently (and some literatures - like the early Christian ones - are commonly affected by them): for example, when the scribes misinterpret the visual hierarchy of the textual ensembles they are copying, and therefore they lay out, for example, new chapters or sections of the same work as if they were major divisions between works, or, inversely, they fall to notice the difference between the copies of two works. Such misunderstandings can also happen when the scribes work from several antigraphs with diverging organisation principles and are unable to synthesise them into a coherent presentation. As a result, the explicit content divisions of the codex by its material content markers do not always faithfully reflect the content divisions from the point of view of text history and philology.

In these cases the analyst lacks a criterion for correctly recognising and then evaluating the observed anomalies: do they frequently appear in the tradition of a given work or set of works? Shall they be considered as individual incongruities or as a common feature of a specific text tradition?

This is why manuscript scholars must combine the history of books with the history of the texts they convey. In most cases, a good knowledge of a work's tradition may allow the analyst to recognise special situations, such as errors in a codex's content divisions. A manuscript scholar does not approach the history of the texts the same ways that a philologist or linguist would, but takes their researches into account in order to understand which meaningful series of words usually circulate together and constitute copies of works.

There is, however, a number of cases where content is presented differently in the witnesses of a given work: there can be, for instance, manuscripts where some chapters appear in different orders or sometimes even as distinct pieces of content. In the tradition of the First Testament this happens, for example, with the book of Daniel, where the stories of Susanna and Bel, which do not appear in the Hebrew tradition, are sometimes copied as a chapter of Daniel, at other 
times before or after this book, as separate pieces of content and not always in the same order. ${ }^{16}$

In any case of inconsistencies within a work's history as reflected in its manuscript tradition (or between the tradition and the work's ancient boundaries as reconstructed by philologists) the analyst must ask him- or herself whether the observed discrepancies result from an 'editorial' intention, which would then reflect how the book producers wanted the users to read it, or if they came about by chance or distraction. Theoretically the examination of a single manuscript diverging from the usual division (of one or more works) can only lead to three possible interpretations, depending on a) whether or not the antigraph was faithfully reproduced (so that one can speak of two separate traditions) and, if it was not, b) whether the observed changes were intentional on the part of the scribes or c) if they simply arose by chance (for example, by a mistake by the scribes or binders).

Let us consider an example in the Codex Sinaiticus of the Greek Bible, ${ }^{17}$ whose $34^{\text {th }}$ quire has lost all folios, but the last one. This contains a portion of 1 Chronicles, which occupies up to the fourth folio of quire 35 (=1 Chronicles 9.27-19.17) with the running title of 2 Esdras in the upper margin; it is then followed abruptly - inside a line, without any visual breaks such a punctuation mark, and without the resulting sentence making any sense - by B Esdras 9.9, which then goes on normally to the end of B Esdras. ${ }^{18}$ This discontinuity would completely escape the attention of someone considering only layout and titles as clues for understanding the content's structure, while a knowledge of both works' tradition would make it clear. Does the situation observed in the Codex Sinaiticus represent a separate tradition? The fact that the sentence linking the two texts does not make sense already points at a mischance, and the reason for this aberrant situation is most likely an accident in the codex's ancestors.

Moreover, taking the manuscript tradition as the first (but not only) criterion allows one to consider as distinct works pieces originally belonging to a larger work from which they have been separately copied; and as distinct works they also have their own independent manuscript transmission. For example, in

16 See for example Munnich, Fraenkel and Ziegler 1999, 20-22, 216-233.

17 GA 01. The remains of the codex are preserved today in four institutions under seven different shelfmarks; see the entry corresponding to the main part (diktyon 38316), with links to the other ones (and their diktyon numbers), in the Pinakes database, <https://pinakes.irht.cnrs.fr/ notices/cote/38316/> (this and all the other links were accessed on 23 March 2021), Andrist 2020, 23 and the web site <www.codexsinaiticus.org $>$.

18 Milne and Skeat 1938, 1-4; Parker 2010, 65-68; Jongkind 2007, 144-147; Parker 2015, 289290. 
polemical collections adversus Iudaeos one finds an independent transmission of Chap. 31 of the Doctrina Patrum, or of Titulus 8 from Euthymius Zigabenus's Panoplia dogmatica. ${ }^{19}$ Similarly, the pararagraph on the four beasts of Ezechiel as symbols of the four gospels in Irenaeus of Lyon's Adversus haereses is copied in many tetraevangelia totally independently from the rest of Irenaeus's work.

This is why in our Syntaxe 1 we developed the concept of UniConts as portions of a codex's overall content, portions whose limits are defined as follows, on the basis of an analysis of the physical text's discontinuity markers as well as on the results of philological and text-historical studies:

- wherever there is a transition in the text from one work to another, even if this transition is not marked in the text; ${ }^{20}$

- wherever there is significant material division of the text, even if it does not correspond to a philologically relevant division;

- (and, of course, by the physical limits of the codex itself).

Our understanding of UniCont is related to, but not identical, to that of 'piece of content', which is a more subjective notion, since the same overall content can be divided into pieces of content in different ways. The differences rely on the notion of 'finite message', which can apply at different levels. In a Tetraevangelium, for instance, does the finite message encompasses the whole book? On the one hand, the answer is 'yes', but each gospel definitely also bears its own finite message. From this narrower point of view, do the evangelist portraits or the prologues belong to the message conveyed by each gospel, or does each of them bear a separate finite message? And within a gospel, should each pericope also be considered as conveying a finite message? The answer to these questions is probably always positive, and all of them would define different - and differently useful - pieces of content; at the same time, a single observer might group portions of the same text in different ways at different times, depending on varying needs. Despite its vagueness, the notion of 'piece of content' retains its usefulness to speak of the content of a codex, when it is not possible to be more precise.

19 Andrist 2016, 347-348, 368-369.

20 There are of course cases where it is not easy to spot the transition from one work to another, especially if one or both are not otherwise known. But this rule makes it possible to bring cases into the analyst's view where portions of text have been mistakenly joined together following accidents in transmission, such as the above discussed situation in Codex Sinaiticus. 
UniConts cannot even be mechanically identified with witnesses, even though there is a close relationship between the two notions: as already mentioned, a UniCont can in fact include BlocConts such as subtitles or socalled 'tail pieces' which are not always considered as part of the witness (see below).

\subsection{Identifying witnesses}

In order to identify the UniConts correctly, we need to answer the important question of how exactly to recognise and delimit a work's witnesses. ${ }^{21}$ What are their identifying features? As is well known, in many manuscript cultures the headings/titles in the manuscripts are not stable (and not even always present) and the identification of a work must therefore rely on its first and last words, which is not without its challenges.

Variants readings have to be dealt with first, since there are no two identical copies of a work, except perhaps extremely short ones. These variant readings may also (and often do) affect the beginning and/or end of the witness and complicate its identification and delimitation. The same difficulty arises when the variants are not the result of accidents but of a systematic revision of the text; in this case it can also happen that two copies of the same work have a significantly different beginning or ending.

Fluid traditions, where one finds radically reworked copies of a work, are an even more difficult challenge. One recognises both their dependency on and their link to a common textual tradition, as well as the uniqueness of the tradition's 'avatar' in this or that specific manuscript. There are also cases where hardly two manuscripts contain the same avatar of the same work. How large must the difference between two avatars of a single textual tradition be before we go from considering them witnesses of the same work to seeing them as two independent works? There is probably no definitive answer to this question.

In several cases the differentiation between works also depends on other factors, such as the analyst's/reader's own way of perceiving things, or his or her contextual need of a more granular description of the works.

In any case the existence of a critical edition (i.e. an edition with is based on a critical study of the witnesses and also provides the users with the main variant readings found in the manuscripts) is very useful, and even more useful if it

21 For a discussion of this problematic question, see Sharpe 2003, in particular 50-57; see examples on pp. 176-183. 
can be searched electronically. In some cases, however, the edition itself can make identifying a text somewhat more difficult, for example if the text of a work from antiquity is presented in a form reconstructed by the editors and not in the way it circulated in medieval manuscripts. If the recognition of the actual shape and boundaries of a work in a given manuscript or set of manuscripts is based solely on its edited form, and neither the history of its tradition nor its physical setting are taken into consideration, the analyst risks applying textual divisions which do not belong to the manuscript but are dictated by a certain philological conception of the text.

\subsection{The internal structure of the UniConts}

Our definition of a UniCont is still insufficient to account for all concrete cases.

Let us consider for example a codex or part of a codex with the following content segmented into ElConts:

Table 1: Example of a series of consecutive BlocConts.

Decoration

Initial Heading/Title

Plain text of the work $=$ Witness

Amen

Ending Heading/Title

Colophon

Decoration

Let us detail the example of the headings/titles.

Are initial or ending headings/titles part of the witness or not? As often, there are several ways to analyse the situation.

In traditional manuscript catalogues the headings are often left unmentioned or are normalised as standard titles for identification purposes. In any cases the cataloguers do not consider them as distinct pieces of content.

In more modern catalogues headings are usually described together with the main text and are often treated no differently from incipits. They are again considered part of the same ensemble as the main text.

In a traditional philological approach the headings as read in the manuscripts are mostly considered not original to the work's production (or revision), 
even though many works were first put into circulation by the author (or the revisers) with a heading.

In paratext studies the title is typically kept distinct from the main text, either as an 'authorial paratext', or as a 'traditional paratext' if it was modified and/or imposed by the tradition.

In both last cases the headings are considered accompanying texts and thus distinct from the plain text, no matter if they were made by the author or added at a later stage. As such, they can be considered autonomous BlocConts.

But are the headings part of the UniCont?

Headings are a rather constant feature in manuscripts (except in the case of mutilated manuscripts or in other special situations) and they may appear in a great variety of forms and show a rich concentration of variant readings. But there are also cases where the heading becomes integrated with the beginning of the main text in a single sentence, or at the end in the form of a tail piece. In the most usual situations, headings not only belong to the devices marking the boundaries between two texts and may aid in differentiating the two corresponding UniConts. They are also part of the greater 'package' to be read or copied as a whole, which most importantly includes the BlocCont(s), which each heading is the heading of.

Similar observations could be made about some other kinds of 'paracontents', such as the Eusebian apparatus in the margins of the gospel manuscripts: they are presented as part of the reading ensemble, or 'copied package', even though they are clearly not part of the plain text.

As manuscript historians, we consider as our main reference the manuscript itself, and the manuscript tradition of a given work is the soundest ground for the judgment we will make. In the Syntaxe 1 we proposed a number of theoretical models concerning the UniConts, among which is the 'Model Cont 2', which presents a fictitious codex bearing 'two or more texts certainly or probably without any link between them in the content. For example, a codex containing a book of the Odyssey, an epistle of Paul, and a small orthographic lexicon, without significant division within these texts'. ${ }^{22}$ In such a case we concluded that we had to do with three UniConts. Although we did not state it openly, we were referring implicitly to copies of works with their usual accompanying material, including their headings and text divisions such as subtitles or section numbers. Seven years later, we still think it is relevant to include these accompanying texts in the same UniCont they belong to. What then should we call them?

22 Syntaxe 1, 105-106. 
On the one hand, they are BlocConts, and each of them usually matches a single ElCont. On the other hand, BlocConts such as headings are also accompanying texts matching the characteristics of paracontents. ${ }^{23}$ Therefore, in our model, headings, colophons and decorative elements used as separation markers may be considered paracontents to the plain text within the same UniCont.

As a result, a UniCont can also be seen as a structured whole, including a 'plain content' and, possibly, a series of paracontents thereto.

But two caveats are needed:

- the paracontents to a plain content are not necessarily all part of the same UniCont to which the plain content itself belongs;

- the plain content itself can in turn be a paracontent to another plain content hosted in the same book. For example, in the case of a prologue to the Gospel of Mark, preceded by the prologue's own title, the title is a paratext to the plain text of the prologue, and the UniCont containing both of them is also a paratext to the Gospel of Mark. ${ }^{24}$

The resulting structure of the Basic Content can be generally modeled as follows:

- Basic Content: in a codex, a series of UniConts; ${ }^{25}$

- UniCont: in a codex, a series of BlocConts, grouped following a codicological and text historical analysis as well as according to the results of philological research (if available);

- BlocCont: in a codex, a series of ElConts, closely related by their meaning and (apparent) common transmission or composition in the codex;

- ElCont: in a codex, a section of the content mechanically defined by visual devices (or the limits of the codex).

\section{UniConts and other types of content}

The discussion above refers mainly to recurring textual content. Let us now add some observations on other types of content.

23 See Andrist 2018.

24 Autonomous basic contents, i.e. contents that are not paracontent of any other content, may also be called core contents.

25 As explained above, 'series' always means 'one or more'. For example here, it covers cases where a codex is made of a single UniCont. 


\subsection{Non-recurring textual contents}

Not all UniConts in a manuscript also occur in other manuscripts, either because there is only one known extant copy of a work, or because they are 'circumstantial' UniConts (such as a colophon or many book epigrams), composed in direct relation to a specific copy of a work and the production of a specific codex.

In the first case the content's heading will usually allow the analyst to understand that he or she is dealing with the copy of a work. The history of texts, however, gives no clues for establishing whether this is a full copy of the whole work, or only of a part of it, or perhaps an autograph witness. Two interesting examples of this difficulties are the texts found in two celebrated papyri: the geographical treaty by Artemidorus of Ephesus in the so-called papyrus of Artemidorus, ${ }^{26}$ and the Gospel of Jesus's Wife; ${ }^{27}$ the fierce debate about their authenticity was made possible by the fact that there is only one extant copy of each in its own UniCont. ${ }^{28}$

As for the limits of circumstantial contents, they are usually determined by their meaning. Let us consider some examples.

Marginal notes to the main text. Marginal scribal or readers' notes are often nonrecurring content, either circumstancial or related to the message of the codex' pieces of content. How should they be considered in relation to the UniConts, for example when a scribe or a reader adds occasional and non-continuous explanations to the main text on different pages of a codex? The analyst has first to decide if each of these ElConts should also be considered a separate BlocCont or if they can be regrouped in one or several larger UniConts; then also if the resulting BlocConts are part of the same UniCont as the text of which they are paratexts. How they can be best described is another question, which we do not address here.

However, marginal notes are not necessarily non-recurring content; their peripheral position does not, for example, exclude their being copies of other works or part of works. They can also be corrections to the plain text consisting only of well-known variant readings. In a case like this how can they be ana-

26 Among many publications, see Canfora 2007. For another point of view see Gallazzi, Kramer and Settis 2008.

27 See now Sabar 2020.

28 According to the latest evidence, it is difficult to consider either of them as anything but a modern forgery. 
lysed? On the one hand, they are part of the work. On the other hand, they do not belong to the main flow of the copy and from the point of view of the layout they are separate contents.

If the marginal corrections are by the hand of the scribe or of an original reviser (that is, someone belonging to the production team and correcting the manuscript before it was put in circulation), it is difficult not to consider them as belonging to the main text; they are intrinsic part of what the producers wanted to 'publish' and thus do not constitute separate content. Technically, they are ElConts which can be grouped into the same BlocCont as the text they correct.

What if they are by a later reader? The analysis, we think, depends also on the viewing angle: from the point of view of production, the notes are certainly separate pieces of content, added to the original content, probably from another source and as part of another project..$^{29}$ But from the perspective of circulation it can be argued that the notes and the main text together also make up a UniCont, though this differs (perhaps not by much) from the original one; the users of the resulting unit have to do with something (more or less) different from what the readers of the original book had.

What if these notes are not just text corrections but variant readings combined with editorial remarks, such as 'in other manuscripts one reads...'? This is clearly another type of (non-recurring) content, which is also a paracontent, since it is closely related to (and even depends on) the main content. If - as in the previous example - they can be attributed to the original production team, they also clearly belong to the same UniCont as the text they refer to but not to the same BlocCont.

Marginalia that have no direct link with the plain text are clearly separate contents.

Colophons. Readers usually have little doubt about the boundaries of a colophon, because of its meaning and layout: it usually immediately follows the plain text, from which it is often separated through a simple device (such as an extra space or a decorative line) and distinguished by a different layout, script and/or ink; moreover, there is often no other portion of the text after it. The colophon is therefore clearly another BlocCont. But is it also another UniCont?

There are several ways to approach the question. One possibility would be always to consider colophons as separate UniConts, because the nature of their

29 Loosely understood as the result of any conscious or unconscious motivation to write something. 
message is different from the main contents of the codex, and, as a result, they are distinct secondary contents. Another solution would make the analysis depend on the situation: if, for example, the codex contains several pieces of basic context and the final colophon applies to all of them, it will be considered paratext to all of them or, alternatively, to the whole book, and will thus have to be analysed as a distinct UniConts. ${ }^{30}$ But if the book contains only one piece of basic content, or several pieces but the colophon applies only to one of them, or if the colophon was accidentally copied from the antigraph, then it might be considered a part of a single 'package' and analysed as being part of the same UniCont; it would also be a paratext of the basic content it applies to.

\subsection{Complex contents}

Up to this point we have dealt almost exclusively with manuscripts whose only contents are texts. Such manuscripts exist, but many others also (or even exclusively) contain other types of content, such as images or pieces of music, and often content types are mixed. How can UniConts be analysed in such situations? ${ }^{31}$

Textual contents with images. There are copies of ancient or mediaeval works accompanied by images or drawings illustrating the plain text. Independent from the question of whether the images originally accompanied the work, they are clearly paracontents to the plain text. No matter if they are a late reproduction of the original work or were created by the scribe or an artist working with him, they are also part of the same UniCont. Such is the case with most of the evangelist portraits in tetraevangelia, as in the below-presented example of Genavensis gr. 19.2 In some instances one can even argue that two different (sets of) copies of a work, the one with an image-paracontent and the other one without it, represent different manuscript traditions of the same work.

In complex cases the images might also receive captions (i.e. small texts within the image itself) which describe or explain some elements of it; these are

30 For colophons as paratexts, see Andrist 2018, 142-143.

31 The following pages contain a theoretical discussion of frequent cases, for which the readers will easily find examples drawn from their own personal experience of manuscripts.

32 Geneva, Bibliothèque de Genève, gr. 19 (diktyon 17169; GA 75); see Pinakes (<https://pinakes. irht.cnrs.fr/notices/cote/17169/>). See also Andrist 2008, including the collation of the quires and the reconstruction of their original sequence. 
pieces of paracontent within a piece of paracontent but they are most probably to be interpreted as part of the same BlocCont.

Works with a 'visual layout'. In some cases, such as the Liber de laudibus Sanctae Crucis by Rabanus Maurus or the visual poems by Theodore Prodromus, the images arise from a particular arrangement of some of the letters composing the text. ${ }^{33}$ In these and similar cases the image is not a separate content and there are no reasons to define a new UniCont. However, since it is difficult to speak of the layout in terms of content, one can say that the layout has a semantic significance.

Isolated images. It may happen that images are painted as a frontispiece to the whole book, for example in the Dioscorides of Vienna, ${ }^{34}$ some deluxe editions of the gospels, or in the Basel edition of Elias of Crete's Commentaries on Gregory Nazianzen. In this last example these images, which are an original composition and cannot be considered copies or recreations of other images, cannot be described in terms of the dynamics between a work and its copies. ${ }^{35}$ As far as an art historian can tell, they are clearly paracontent to the whole of what is copied in the book or, alternatively, to the whole book. They must be therefore considered distinct UniConts. If several images are painted with the same purpose within the same project, and they are placed in the codex one after the other, we might ask ourselves whether there are as many UniConts as there are images or whether all of them as a group should count as one: we incline towards considering them all together as a single UniCont.

Pieces of music. Liturgical manuscripts with systematic musical notation are also examples of works mixing textual and non-textual elements. In this case it is not possible to separate the notation from the text, nor can the one be always clearly considered paracontent to the other. They are also, together, part of the same UniCont.

Syllogai and collections of excerpta. Complex content can also occur in the case of textual works, for example the sylloge, i.e. a series of more or less small works

33 See Hörandner 1990.

34 Vienna, Österreichische Nationalbibliothek, med. gr. 1 (diktyon 71026); see Pinakes (<https://pinakes.irht.cnrs.fr/backend/cotes/edit/id/71026/>).

35 Basel, Universitätsbibliothek, A.N. I. 8 (diktyon 8896); see Pinakes (<https://pinakes.irht. cnrs.fr/notices/cote/8896/>). See also Krause 2018 and now Macé and Andrist 2020. 
(or part of works) which tend to be copied together in more or less the same order. ${ }^{36}$ One can argue that they can be considered together as a copy of a single work. Should they be analysed as one UniCont? On the one hand, in those situation where they were originally independent works one is inclined to consider them distinct UniConts. On the other hand however, there might be traditions in which the scribes (and their readers) clearly perceive them as constituting a witness to a single work. Both the sylloge's textual tradition (i.e. whether other witnesses of it exist or not) and the visual devices used to separate the UniConts in the codex usually help one understand what the scribes' and the readers perception was and to decide if the sylloge should be considered a single UniCont, or not. This can also be the case with collections of excerpta. The smaller the excerpta, the higher the chances that they would be best perceived as parts of a single UniCont.

Chains. As a final example, we wish to touch upon the question of chains, or catenae - a form of systematic biblical commentary made up of 'chained' excerpts of earlier commentators -, whatever their layout may be. ${ }^{37}$ Should the whole set of scholia and the biblical text be analysed as two (or more) works? Or is it more relevant to consider all of them together as a single complex work, which thus includes several previous works or parts of works? In any case, are the scholia paratexts to the plain text of the Bible? Or are the scholia the plain text, and the biblical text a necessary series of quotations, such as many commentators cite when expounding? Or does the page layout decide which one is the plain text?

Independent of the answer, in a codex bearing, for example, a chain to the Pauline Epistles, how many UniConts are there a priori? One, because the chain was created in a single undertaking? Or fourteen, one per epistle? Again the answer depends on several factors: in part upon the visual devices at the places of transition between the recognised BlocConts; in part also upon the answer to the question above of how many works are considered to be in the book; but also upon the new question if, in special situations such as a complex work, a UniCont can cover only a portion of the works content, rather than the whole work as a minimum extent.

36 On the sylloge (from a codicological point of view), see Maniaci 2004, 82-86, with related bibliography.

37 For a recent point of entry into a complex literature, see Lorrain 2020. For an introduction to the issue see Maniaci 2002. 
The paragraphs above do not take into consideration all the situations encountered in codices, and certainly leave many questions open, that we hope to address at a further stage in our thinking.

\section{UniConts and the structure of the basic content}

Now that we have presented what a UniCont is and how to recognise it, let us broaden the perspective and inquire into its relation to the other types of content in the codex and to the basic content's structure. Again, in this section we leave aside questions tied to a book's evolution, be they mutilations, restorations, the addition of contents, etc.

\subsection{UniConts and the contents of a codex}

We first return to the various types of contents in a codex. How do UniConts fit into this picture?

In the Syntax 2 we define a book as 'a transportable object, made to last, created or used to receive, share, and transmit content in an orderly and immediately readable manner'. According to this definition a book was conceived in order to host content. The specific content that the book was conceived to host is its 'main content', for example a corpus of imperial laws or a series of songs to be sung during a church office. But the main content never comes bare:

- as we have seen, it is always accompanied by (sometimes numerous) paracontents; and

- in some cases the book producers also add 'secondary contents', such as copies of other works, or circumstantial contents which are not central to the project. ${ }^{38}$

Based on the explanation above, we can summarise the various types of content in a codex in the following table: ${ }^{39}$

38 Analytically, the main content and, if extent, the secondary content are made of a series of autonomous core contents accompanied by their paracontents. Ultimately, all of these paracontents depend on a core content, directly or indirectly. On core content, see above footnote 24 . 39 For the sake of making this chart comparable with that presented at a conference in Oslo in 2014 (see Andrist 2018, 147), categories B and C, concerning the transformation of the codex, are also mentioned. Two significant differences between the two charts have to do with the 
Table 2: Summary of the various types of content in a codex.

A. Book-producer's content

1. Basic content

a. Main content

b. Secondary content

2. Functional content

3. Ancillary content

a. Side-content

b. Contents on re-used material

B. Post-production content

C. Re-made book content

Paracontent is not included here, since it appears at every level as dependent content within each of the types listed. As mentioned above, they do belong to the same content type or sub-type as the plain content they depend on.

UniConts also can operate at every level of the basic content; they are primarily relevant to understanding the structure of each of these levels.

\subsection{UniConts, perimeters and a codex's paratextual structures}

Having presented a book production's main contents, we can now inquire as to how the paracontents (mainly paratexts) help give structure to the codex's main content, and how they relate to UniConts. To illustrate these points let us consider the simple case of the tetraevangelium Genavensis gr.19. The following table summarises the main content of the first half of the codex; the lines separate what we would describe as distinct UniConts:

integration of the functional contents into the classification and the systematic subordination of paracontents to the independent contents they are attached to. 
Table 3: Content of the first half of Genavensis gr. 19.

\begin{tabular}{|c|c|}
\hline fols $5^{r}-6^{v 40}$ & $\begin{array}{l}\text { Introduction to Matthew } \\
\text { polychrome decoration line } \\
\text { golden title of the introduction } \\
\text { introduction to Matthew (in black) } \\
\text { empty space ( } 4 \text { lines) }\end{array}$ \\
\hline fols $6^{r}-7^{v}$ & $\begin{array}{l}\text { Capitula for Matthew } \\
\text { polychrome decoration line } \\
\text { golden title to the capitula } \\
68 \text { capitula (in red) } \\
\text { empty space ( } 3 \text { lines) }\end{array}$ \\
\hline fols $8^{r}-13^{v}$ & $\begin{array}{l}\text { Letter to Carpian and Eusebian canons } \\
\text { polychrome decoration line } \\
\text { golden title of the epistle } \\
\text { Epistula ad Carpianum (in red) } \\
\text { empty half-line } \\
\text { additio to the epistle (in red; small marginal initial); } \\
8 \text { pages with the illuminated canons }\end{array}$ \\
\hline fols $14^{r}-15^{r}$ & empty \\
\hline fols $15^{v}-148^{r}$ & $\begin{array}{l}\text { Gospel of Matthew } \\
\text { (full page) portrait of Matthew } \\
\text { (half page) painting representing the nativity with the } \\
\quad \text { ancestors of Jesus in the margins } \\
\text { golden title of the gospel } \\
\text { Gospel of Matthew (in black) with usual paracontents } \\
\text { empty space at the end (11 lines) }\end{array}$ \\
\hline fols $148^{v}-149^{v}$ & $\begin{array}{l}\text { Capitula for Mark } \\
\text { simple decoration line (in red) } \\
\text { title of the capitula (in red) } \\
48 \text { capitula (in red) } \\
\text { empty space ( } 6 \text { lines) }\end{array}$ \\
\hline fol. $150^{\mathrm{rv}}$ & $\begin{array}{l}\text { Introduction to Mark } \\
\text { simple decoration line (in red) } \\
\text { title of the introduction (in red) } \\
\text { introduction to Mark (in black) } \\
\text { empty space ( } 2 \text { lines) }\end{array}$ \\
\hline fol. $151^{r}$ & empty \\
\hline
\end{tabular}

$\overline{40 \text { Fols } 1}$-4 are anterior flyleaves. 
Table 3 (continued).

\begin{tabular}{|c|c|}
\hline fols $151^{v}-232^{r}$ & $\begin{array}{l}\text { Gospel of Mark } \\
\text { (full page) portrait of Mark } \\
\text { (half page) painting representing the baptism of Jesus } \\
\text { golden title of the gospel } \\
\text { Gospel of Mark (in black), with the usual paracontents } \\
\text { (no empty space) }\end{array}$ \\
\hline
\end{tabular}

etc.

Two introductory pieces to Matthew, placed in first position, are separated from the gospel they introduce by the Eusebian material, because of a misplacement of the folios during a restoration. This might seem strange at first sight, but is in fact quite common.

The introduction and capitula to Matthew are clearly presented as distinct UniConts, each of them beginning on a new page, with equally important titles and some empty space at the end.

Recent research has confirmed that the Eusebian canons and the Letter to Carpian, which introduces them, are two parts of the same work..$^{41}$ Should they then be counted as making up a single UniCont which includes two (or more) BlocConts? Or, if one accepts the idea presented above, that the copy of a complex work can be analysed as more than one UniCont, can one consider there are two UniConts here? We leave the question open, and present the two texts (tendentially) as one UniCont in Table 3 above, but (clearly) as two UniConts in Table 4 below.

There is instead no doubt that the portrait and the paintings at the beginning of Matthew's Gospel (fols $15^{\mathrm{v}}-16^{\mathrm{r}}$ ) were conceived as a grandiose opening to it.

Overall the placement of the paracontents to Mark is similar to that adopted for the first gospel, except that the capitula and introduction, whose relative position has been swaped, are not separated from the gospel itself. This separation however is an accident, and there is no reasons to treat both sets of paratexts differently. The empty page which separates them from the opening of the gospel stresses their less important but distinct position as introductory paracontents to Mark.

41 Wallraff 2021. 
Paratextual 'perimeters'. The example of Genavensis gr. 19 illustrates an important aspect of paratexts. In this codex, as in many others, a specific structure of the content is immediately recognisable: each biblical book and its set of accompanying paracontents constitute a certain coherent whole. This ensemble can be called the 'perimeter' of this biblical book. ${ }^{42}$ For example, here the perimeter of Mark runs from fol. $148^{\mathrm{v}}$ to fol. $232^{\mathrm{r}}$ and includes three UniConts:

- 1) the one centred on Mark (which is a main content of the book), including its paracontents, ${ }^{43}$

- 2 and 3) the two other UniConts - the Capitula and the introduction -, which are also paracontents of Mark. ${ }^{44}$

Since the grouping of the contents related to Mark is directly linked to a single main content, we define it as a 'simple perimeter', which is distinct from other simple perimeters (to the other gospels) contained in the same codex.

But wider perimeters can often also be recognised in a codex, including several simple perimeters where the paracontents depend on several autonomous main contents and thus form a larger whole with them. These are then referred to as 'complex perimeters', which may include other complex perimeters or even the whole book. For example, here the Letter to Carpian and the Canon Tables form, together with the four simple perimeters of the Gospels, a complex perimeter encompassing all of the codex's original basic contents. ${ }^{45}$

The original relation between the perimeters, the UniConts and one possible interpretation of the related BlocConts is summarised in the following Table 4.

This very common example shows how the UniConts operate first of all as a mean for grouping a series of paracontents around another component of basic content. Second, they bring some structure to the the main basic contents. And thirdly, they help understand and communicate how the scribes understood the codex's structure and its content.

42 Of course, paratexts can also have their own perimeters.

43 These could be called 'intra-UniCont paracontents', forming an 'elementary simple perimeter' with Mark.

44 These could be called 'extra-UniCont paracontents', making up an 'extended simple perimeter' to Mark.

45 For more explanations and another example, see Andrist 2020, 12-14. 
Table 4: Structure of the content in the first half of Genavensis gr. 19.

\begin{tabular}{|c|c|c|c|}
\hline $\begin{array}{l}\text { Perimeters } \\
\text { complex simple }\end{array}$ & $\begin{array}{l}\text { UniConts } \\
\text { (folios) }\end{array}$ & $\begin{array}{l}\text { BlocConts } \\
\text { (folios) }\end{array}$ & \\
\hline \multirow[t]{8}{*}{ Eusebiana } & $8^{r}-9^{v}$ & $\begin{array}{l}8^{r} \text { inc. } \\
8^{r}-9^{v} \text { inc. }\end{array}$ & $\begin{array}{l}\text { golden title (following a polychrome decoration line) } \\
\text { Letter to Carpian (in red) }\end{array}$ \\
\hline & & $9^{\mathrm{v}}$ des. & additio to the letter \\
\hline & $10^{r}-13^{v}$ & & $\begin{array}{l}\text { Eusebian canons - } 8 \text { pages with the illuminated } \\
\text { canons }\end{array}$ \\
\hline & $14^{\mathrm{nv}}$ & & (empty) \\
\hline & $5^{r-v}$ & $\begin{array}{l}5^{r} \text { inc. } \\
5^{r-v}\end{array}$ & $\begin{array}{l}\text { golden title (following a polychrome decoration line) } \\
\text { Introduction to Matthew (in black) - empty space } \\
\text { at the end, } 4 \text { lines }\end{array}$ \\
\hline & $6^{r}-7^{v}$ & $\begin{array}{l}6^{r} \text { inc. } \\
6^{r}-7^{v}\end{array}$ & $\begin{array}{l}\text { golden title (following a polychrome decoration line) } \\
\text { Capitula of Matthew (in red) - empty space at the } \\
\text { end, } 3 \text { lines }\end{array}$ \\
\hline & $15^{r}$ & & (empty) \\
\hline & $15^{\mathrm{v}}-148^{\mathrm{r}}$ & $\begin{array}{l}15^{\mathrm{v}} \\
----- \\
16^{\mathrm{r}} \text { inc. } \\
----- \\
16^{\mathrm{r}} \text { med. } \\
16^{\mathrm{r}} \text { des.- } \\
148^{\mathrm{r}} \\
\end{array}$ & $\begin{array}{l}\text { full-page portrait of Matthew } \\
\text { painting representing the nativity with the } \\
\text { ancestors of Jesus in the margins } \\
\text { golden titel (in enlarged script) } \\
\text { Gospel of Matthew (in black), with usual } \\
\text { paracontents - empty space at the end, } 11 \text { lines }\end{array}$ \\
\hline \multirow[t]{4}{*}{ Mark } & $\begin{array}{l}148^{v}- \\
149^{v}\end{array}$ & $\begin{array}{l}148^{v} \text { inc. } \\
148^{v}-149^{v}\end{array}$ & $\begin{array}{l}\text { title (in red, following a simple red decoration line) } \\
\text { Capitula of Mark (in red) - empty space at the } \\
\text { end, } 6 \text { lines }\end{array}$ \\
\hline & $150^{\mathrm{rv}}$ & $\begin{array}{l}150^{\mathrm{r}} \text { inc. } \\
150^{\mathrm{rv}}\end{array}$ & $\begin{array}{l}\text { title (in red, following a simple red decoration line) } \\
\text { Introduction to Mark (in black) - empty space at } \\
\text { the end, } 2 \text { lines }\end{array}$ \\
\hline & $151^{r}$ & & (empty) \\
\hline & $\begin{array}{l}151^{\mathrm{v}}- \\
232^{r}\end{array}$ & $\begin{array}{l}151^{v} \\
152^{r} \text { inc. } \\
152^{r} \text { med. } \\
152^{r} \text { des.- } \\
232^{r}\end{array}$ & $\begin{array}{l}\text { full-page portrait of Mark } \\
\text { painting representing the baptism of Jesus } \\
\text { golden titel (in enlarged script) }\end{array}$ \\
\hline
\end{tabular}




\section{Conclusion}

As readers will have noticed, the pages above do not arrive at a final answer to the central issue of the content in a codex, but rather offer the first fruits of an ongoing theoretical work and share a series of ideas and thoughts on the UniConts, the BlocConts, the work's copies, the paracontents and their related perimeters, and on the other types of contents. They raise some questions and pass by others, for example the 'geography' of the various contents and the limits of paratextuality. We hope the readers will help us to better define and further develop our reflection on this central topic for the understanding of the production and subsequent history of the codex.

\section{References}

Andrist, Patrick (2008), 'Particularités de la couture en deux blocs du Genavensis grec 19', in Basile Atsalos and Niki Tsironi (eds), Actes du Vle Colloque International de Paléographie Grecque (Drama, 21-27 septembre 2003) (Biblioamphiastîs-Parartîma, 1), 3 vols, Athens:

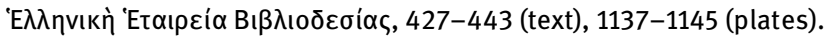

Andrist, Patrick (2016), Les codex grecs adversus Iudaeos conservés à la Bibliothèque Vaticane (s. xi-xvi). Essai méthodologique pour une étude des livres manuscrits thématiques (Studi e Testi, 502), Vatican City: Biblioteca Apostolica Vaticana.

Andrist, Patrick (2018), 'Toward a definition of paratexts and paratextuality: the case of ancient Greek manuscripts', in Liv Ingeborg Lied and Marilena Maniaci (eds), Bible as Notepad. Tracing Annotations and Annotation Practices (Manuscripta Biblica, 3), Berlin: De Gruyter, 130-149.

Andrist, Patrick (2020), 'Au croisement des contenus et de la matière : l'architecture des sept pandectes bibliques grecques du premier millénaire. Étude comparative sur les structures des contenus et de la matérialité des codex Vaticanus, Sinaiticus, Alexandrinus, Ephraemi rescriptus, Basilianus, 'Pariathonensis' et de la Biblia Leonis', Scrineum, 17: 5-106 [online: <https://oajournals.fupress.net/index.php/scrineum/article/view/11466> (accessed on 23 March 2021)].

Andrist, Patrick, Paul Canart and Marilena Maniaci (2013), La syntaxe du codex. Essai de codicologie structurale (Bibliologia, 34), Turnhout: Brepols.

Canfora, Luciano (2007), The true history of the so-called Artemidorus papyrus, Bari: Edizioni di Pagina.

Ciotti, Giovanni, Michael Kohs, Eva Wilden, Hanna Wimmer and the TNT working group (2018), Definition of Paracontent (Occasional Paper, 6), Hamburg: Centre for the Study of Manuscript Cultures [online: 〈http://www.manuscript-cultures.uni-hamburg.de/papers_e.html> (accessed on 23 March 2021)].

Gallazzi, Claudio, Bärbel Kramer and Salvatore Settis (2008), Il papiro di Artemidoro: (P.Artemid.), 2 vols, Milan: Edizioni Dedalo. 
Hörandner, Wolfram (1990), 'Visuelle Poesie in Byzanz. Versuch einer Bestandesaufnahme', Jahrbuch der Österreichischen Byzantinistik, 40: 1-42.

Jongkind, Dirk (2007), Scribal Habits of Codex Sinaiticus (Text and Studies, 5), Piscataway, N): Gorgias.

Krause, Karin (2018), 'Celebrating Orthodoxy: Miniatures for Gregory the Theologian's 'Unread' Orations (Ms. Basiliensis AN I 8)', Jahrbuch der Österreichischen Byzantinistik, 68: 133-155.

Lorrain, Agnès (2020), 'Autour du Vaticanus gr. 762 : notes pour l'étude des chaînes à présentation alternante', Byzantion, 90: 67-95.

Macé, Caroline and Patrick Andrist (2020), 'Understanding the Genesis of a Multi-Layered Byzantine Manuscript. The Illuminated Copy of Elias of Crete's Commentary on Gregory Nazianzen (Basel, UB, AN I 8)', Jahrbuch der Österreichischen Byzantinistik, 70: 289-304.

Maniaci, Marilena (2002), “'La serva padrona”. Interazioni fra testo e glossa sulla pagina del manoscritto', in Vincenzo Fera, Giacomo Ferraù and Silvia Rizzo (eds), Talking to the Text. Marginalia from Papyri to Print. Proceedings of a Conference held at Erice, 26 September - 3 October 1998, as the 12th Course of International School for the Study of Written Records (Percorsi dei classici), 2 vols, Messina: Centro Interdipartimentale di Studi Umanistici.

Maniaci, Marilena (2004), 'Il codice greco “non unitario”. Tipologia e terminologia', in Edoardo Crisci and Oronzo Pecere (eds), Il codice miscellaneo, tipologia e funzioni. Atti del convegno internazionale (Cassino, 14-17 maggio 2003) (Segno e testo, 2), Cassino: Università degli studi di Cassino, 75-107.

Munnich, Olivier, Detlef Fraenkel and Joseph Ziegler (1999), Susanna, Daniel, Bel et Draco, editio secunda (Septuaginta. Vetus Testamentum Graecum, 16.2), Göttingen: Vandenhoeck \& Ruprecht [first edn by Joseph Ziegler, ibidem, 1952].

Parker, David (2010), Codex Sinaiticus: The Story of the World's Oldest Bible, London: British Library.

Sabar, Ariel (2020), Veritas: A Harvard Professor, A Con Man and The Gospel of Jesus's Wife, New York: Anchor, 2020.

Sharpe, Richard (2003), Titulus: Identifying Medieval Texts: An Evidence-Based Approach, Turnhout, Brepols.

Wallraff, Martin (forthcoming 2021), Die Kanontafeln des Euseb von Kaisareia. The Canon Tabels of Eusebius of Caesarea. Critical Edition and Analysis. Untersuchung und kritische Edition (Manuscripta Biblica, 1), Berlin: De Gruyter. 